\title{
PURIFICACIÓN DE IgY CONTRA LA SUBUNIDAD NR3 DEL RECEPTOR NMDA DE CEREBRO DE RATA
}

\section{Purification of IgY against the NR3 subunit of the rat brain NMDA receptor}

\author{
Gina Méndez C, ${ }^{1}$ M.Sc, Edgar Reyes M, ${ }^{2 *}$ M.Sc, Raúl Poutou P, ${ }^{3}$ Ph.D, \\ Balkys Quevedo $H,{ }^{3}$ M.SC, Leonardo Lareo, ${ }^{1}$ Ph.D.
}

\begin{abstract}
${ }^{1}$ Pontificia Universidad Javeriana. Departamento de Nutrición y Bioquímica. Bogotá, Colombia. 'Universidad Nacional de Colombia. Departamento de Química. Bogotá, Colombia. ${ }^{3}$ Pontificia Universidad Javeriana. Departamento de Microbiología. Grupo de Biotecnologia Ambiental e Industrial. Bogotá, Colombia. * Correspondencia: eareyesm@unal.edu.co
\end{abstract}

Recibido: 27 de Octubre de 2007; Aceptado: 27 de Febrero de 2008

\section{RESUMEN}

Objetivo. Obtener anticuerpos tipo IgY contra péptidos sintéticos de las subunidades NR3A y NR3B del receptor NMDA de ratas, para reconocer y seguir la expresión de estas subunidades en extractos de cerebro de rata de diferentes edades. Materiales y métodos. Se diseñaron dos péptidos empleando los sistemas de la base de datos Entrez y el programa ClustalWPBI L de alineamientos múltiples contra las subunidades NR3A y NR3B del receptor NMDA; una vez sintetizados por el método SSPS-fmoc fueron utilizados para inocular gallinas (Gallus gallus, variedad Hy Line Brown) de 16 semanas de edad; al cabo de 57 días postinoculación se purificó IgY específica y se enfrentaron a extractos de cerebro de rata postnatal y adulta. Resultados. Se detectaron las subunidades NR3A y NR3B y se relacionó su expresión con la edad del animal; siendo mayor la expresión de la subunidad NR3A en extracto de cerebro de rata postnatal. No se encontró diferencia marcada en la expresión de la subunidad NR3B en las edades mencionadas. Conclusiones. Esta es la primera investigación que emplea proteína nativa para el reconocimiento de la subunidad NR3 del receptor NMDA, lo cual muestra la especificidad de los anticuerpos generados y contribuye con el entendimiento de las funciones de este receptor y su relación con la regulación de la memoria espacial.

Palabras clave: Subunidad NR3, receptor NMDA, IgY, rata, cerebro. 


\section{ABSTRACT}

Objective. To obtain IgY antibodies against synthetic peptides of NR3A and NR3B subunits of the rat NMDA receptor, to recognize and follow the expression of these subunits in rat brain extract at different ages. Materials and methods. By using Entrez data base and ClustalW-PBI L program for sequence alignment two peptides against NR3A and NR3B subunits of the NMDA receptor were designed, Once synthesized by SSPS-fmoc method, peptides were then inoculated into 16-week-old chickens (Gallus gallus, var. Hy Line Brown). After 57 days specific IgY was purified and confronted with postnatal and adult rat brain extract. Results. Both subunits NR3A and NR3B were detected and their expression was related to rat age. The level of expression of NR3A was higher in postnatal rat brain extract; no marked differences in expression of NR3B were found for either age. Conclusions. This is the first research using native protein for recognition of the NR3 subunit of the NMDA receptor It shows the antibody specificity and contributes to understanding the receptor's functions and its relation to spatial memory regulation.

Key words: NR3 subunit, NMDA receptor, IgY, rat, brain.

\section{NTRODUCCIÓN}

El receptor de glutamato activado por $\mathrm{N}$-Metil-D-Aspartato con la glicina como co-agonista está localizado sobre las membranas post-sinápticas del sistema nervioso central (SNC). Este receptor conforma un canal iónico relacionado con procesos de memoria espacial y aprendizaje. Hasta el momento no se conoce con exactitud la estequiometría del receptor, sin embargo, se han propuesto diferentes modelos que lo describen como un complejo formado por al menos una subunidad NR1, una subunidad NR2 y/o una subunidad NR3, las cuales le proporcionan las características estructurales y funcionales al receptor (1).

Los estudios realizados en cerebro de rata han demostrado que estas subunidades se subdividen en NR1-1 a NR1-8, NR2-A a NR2-D y NR3A y NR3B (1). La subunidad NR3 regula el paso de iones a través del receptor. Se ha demostrado que las subunidades de la NMDA, NR1-1 y NR2 pueden asociarse de forma independiente con la NR3A; subunidad que se ensambla a nivel del retículo endoplasmático ( $R E)$ pero no se dirige a las membranas post-sinápticas sin la coexpresión con NR1, lo cual justifica que no se pueda encontrar en forma homomérica (2). Uno de los primeros estudios realizados para la subunidad NR3 fue la clonación de un nuevo miembro de la familia del receptor tipo NMDA de cerebro de rata, denominado chi-1 (3). Posteriormente se aisló el ARNm que codifica para un polipéptido similar a la subunidad chi- 1 , denominado NMDAR-L (4); actualmente esta subunidad se conoce como NR3A (5). Durante la primera semana postnatal los niveles NR3A se encuentran elevados principalmente en membranas postsinápticas, médula espinal, tallo cerebral, hipotálamo, tálamo, región de CA1 del hipocampo y amígdala; luego la expresión disminuye gradualmente y en la edad adulta se detecta únicamente en el tálamo, las amígdalas y el núcleo del tracto olfatorio lateral (3). La subunidad NR3A al estar coexpresada con otras subunidades reduce el flujo de iones inducido por agonistas (3). Así, al estar unida a NR1 y NR2 actúa de manera inhibitoria en el receptor tipo NMDA, reduciendo la conductancia unitaria del canal, la sensibilidad al bloqueo con $\mathrm{Mg}^{+2}$ y la permeabilidad al $\mathrm{Ca}^{2+}$, además, aumenta el tiempo medio de apertura del canal $(5,6)$. De esta manera, la subunidad NR3A sirve como regulador del receptor y controla la amplitud y el flujo de $\mathrm{Ca}^{2+}$ (7).

Algunos autores (6) han hablado de la existencia de dos isoformas de la NR3A, una de ellas denominada NR3-larga, la cual tiene una inserción de $60 \mathrm{pb}$ en la zona del gen que codifica para el dominio intracelular del 
C-terminal, forma que predomina en la corteza occipital, el cerebelo y el tálamo. La otra denominada NR3-corta se ha detectado sólo en la región del cerebelo. En ratas recién nacidas la expresión postnatal (primera semana) de la NR3-corta es superior a la NR3-larga y en los animales adultos la NR3-larga se expresa más que la NR3-corta (6).

El análisis de la secuencia de un clon NR3B, reveló un ADNc con al menos nueve exones, que codificaban para una proteína de 1003 aminoácidos, confirmando la existencia de un subtipo nuevo, perteneciente a la subunidad NR3 del receptor de NMDA, con características similares a la NR3A, por lo que se denominó NR3B. Entre las características más sobresalientes, se encontró un cambio en el motivo YTANLAAF del NMDA donde la fenilalanina es sustituida por valina; este motivo es altamente conservado entre las diferentes subunidades del receptor (8). Son muy pocos los estudios relacionados con la subunidad NR3B y algunos de ellos sugieren que no puede ser sustituida o co-expresada con NR1 y/o NR2A, pues resultaría en la formación de canales electrofisiológicamente disfuncionales.

Adicionalmente se conoce que esta subunidad se expresa de manera exclusiva en motoneuronas somáticas, en el núcleo del nervio craneal que incluye el motor trigeminal y el núcleo facial y en el cuerno de la espina anterior; el cual controla el movimiento somático. Además, la baja regulación y la disfunción de NR3B incrementan la actividad del receptor, lo cual aumenta la vulnerabilidad de las neuronas a la excitotoxicidad (7). Todos los estudios de la NR3 se han desarrollado en cerebro de ratón, para lo cual se han empleado herramientas computacionales y de biología molecular. Sin embargo hasta el momento no se ha trabajado con la proteína nativa aislada de la fuente natural.

Las IgY son una clase especial de inmunoglobulinas que se han estudiado desde hace más de treinta años. Las IgY han sido caracterizadas en aves, reptiles y anfibios, cuyos sistemas inmunes, aunque algo similares a los de mamíferos, difieren principalmente en que la transferencia de la inmunidad ocurre directamente a la yema del huevo a diferencia de la transferencia a través de la placenta o el calostro; de aquí su denominación como inmunoglobulina $Y$ (IgY) (9-11). La IgY, al igual que las otras inmunoglobulinas de bajo peso molecular, posee dos cadenas pesadas $(P)$ y dos cadenas livianas ( $L$ ), unidas por puentes disulfuro; con un peso molecular de $\sim 180 \mathrm{kDa}$, con excepción de la forma truncada encontrada en patos, gansos y tortugas, la cual tiene un peso molecular de $120 \mathrm{kDa}$ por carecer de dos dominios C-terminales en la cadena pesada (12). A diferencia de la IgG, la IgY no contiene región bisagra, por lo cual es una molécula con menor flexibilidad; las cadenas $P$ de la IgY pesan entre 67 y 70 $\mathrm{kDa}$, cada una posee un dominio variable y cuatro dominios constantes al igual que la IgE, a diferencia de la IgG que posee un dominio constante menos. Esta región constante adicional se une a dos cadenas de carbohidratos y es la razón por la que la IgY tiene un peso molecular superior a la IgG (12). Las cadenas $L$ tienen un peso molecular de $225 \mathrm{kDa}$ cada una y posee un dominio variable y uno constante al igual que la IgG $(9,11)$.

El objetivo de este estudio fue generar, aislar y purificar anticuerpos policlonales tipo IgY contra péptidos sintéticos correspondientes a segmentos de las subunidades NR3A y NR3B del receptor NMDA de ratas. Para hacer el reconocimiento y seguimiento de la expresión de estas subunidades en extractos de cerebro de rata de diferentes edades.

\section{MATERI ALES Y MÉTODOS}

\section{Generación de anticuerpos policlonales contra la subunidad NR3 del receptor tipo NMDA. Para diseñar los péptidos correspondientes a las subunidades NR3A y NR3B de cerebro de rata, se buscaron las secuencias reportadas en el sistema Entrez (http://www.ncbi.nlm.nih.gov) para estas subunidades. Las secuencias encontradas se alinearon con las demás subunidades del receptor NMDA y con las subunidades de los receptores ionotrópicos y metabotrópicos de}


glutamato, a través del programa ClustalWPBIL (13) para alineamiento múltiple. Los péptidos diseñados fueron sintetizados por la Fundación Instituto de Inmunología de Colombia (FIDIC), a través del método de síntesis de péptidos en fase sólida (SPPS) Fmoc $(14,15)$.

I nmunización de los animales. Una vez obtenidos los péptidos, se inmunizaron 6 gallinas (Gallus gallus, variedad Hy Line Brown) de 16 semanas de edad ( 3 por cada péptido) y otras dos gallinas fueron utilizadas como control. Las gallinas fueron acondicionadas en jaulas individuales con alimentación "ad limitum". Una vez comenzado el período de postura y de producción regular ( 1 huevo/día) se inició la etapa de inoculación de los péptidos emulsificados con adyuvante completo de Freund (Sigma). Las gallinas fueron inmunizadas intramuscularmente en varias zonas de la región pectoral. Las inmunizaciones fueron reforzadas en otras dos oportunidades a intervalo de 10 días, sustituyendo el adyuvante completo por adyuvante incompleto de Freund (Sigma, St Louis, MO, USA).

\section{Extracción, purificación e identificación} de anticuerpos específicos. Los huevos fueron recolectados diariamente, marcados y conservados a $4^{\circ} \mathrm{C}$ hasta su posterior utilización. Cada yema fue lavada con $\mathrm{H}_{2} \mathrm{O}$ desionizada para lograr la separación de la clara y de la membrana vitelina; las yemas resultantes fueron diluidas 10 veces con $\mathrm{H}_{2} \mathrm{O}$ destilada y se equilibró el $\mathrm{pH}$ a $5.0 \pm 0.2$. Posteriormente la mezcla se mantuvo en agitación constante durante toda la noche a $4 \stackrel{\circ}{ } \mathrm{C}$. El sobrenadante fue separado por centrifugación $6000 \times \mathrm{g}, 30 \mathrm{~min}$., 4으 en una centrifuga BECKMAN L-71, luego se precipitó con $\left(\mathrm{NH}_{4}\right)_{2} \mathrm{SO}_{4}$ al $60 \%(\mathrm{p} / \mathrm{v})$ de saturación (15-17) y se dejó en agitación constante a $4 \stackrel{\circ}{ } \mathrm{C}$ durante 3 horas (18). Pasado este tiempo, la solución se dejó en reposo durante $12 \mathrm{~h}$ a $4^{\circ} \mathrm{C}$ y se centrifugó a 10000 x g, 30 min., a $4 \stackrel{\circ}{\circ}$. El precipitado salino fue resuspendido en tampón A (tampón fosfato $50 \mathrm{mM}, \mathrm{pH} 7.5 \pm 0.2, \mathrm{Na}_{2} \mathrm{SO}_{4}$ $0.5 \mathrm{M})$. A partir de este nuevo extracto se purificó la IgY total empleando cromatografía tiofílica, en "Sepharose 4B" (Sigma, St Louis, MO, USA) previamente activada con divinil sulfona, DVS (Fluka, St Louis, MO, USA), según la metodología sugerida por Hansen (19). En este proceso se emplearon columnas (BioRad ${ }^{\mathrm{TM}}$ ) de $3 \mathrm{ml}$ y se colectaron fracciones de $\sim 1.0 \mathrm{ml}$, hasta disminución de la $\mathrm{Abs}_{280 \mathrm{~nm}}$ (absorbancia), la cual fue seguida por espectrofotometría UV empleando un espectrofotómetro ( $\mathrm{SmartS}$ pect ${ }^{\mathrm{TM}} 3000$ BioRad $^{\mathrm{TM}}$ ). Para eluir las proteínas retenidas, se utilizó el tampón $B$ (tampón fosfato $50 \mathrm{mM}, \mathrm{pH} 7.5 \pm 0.2$ ) y se recolectaron fracciones de $1.0 \mathrm{ml}$ las que fueron monitoreadas por $\mathrm{Abs}_{280 \mathrm{~nm}}$.

La purificación de las IgY específicas se realizó mediante cromatografía de afinidad, utilizando como soporte AffiGel-10 (BioRad ${ }^{\mathrm{TM}}$ ) al cual se acoplaron los péptidos sintéticos (acople acuoso) (20). La columna fue equilibrada con tampón $C$ (tampón fosfato $0.1 \mathrm{M}, \mathrm{pH} 7.5 \pm 0.2$ ). El material retenido fue eluido con $1 / 3$ del volumen de la columna compuesto de $1 \mathrm{mg} / \mathrm{ml}$ del péptido sintético en tampón C. La concentración de proteínas fue determinada por el método de Bradford (21), en lector de microplacas modelo 550 (BioRad ${ }^{\mathrm{TM}}$ ).

SDS-PAGE. Los extractos fueron analizados por SDS-PAGE, 7.5\%, de acuerdo con el procedimiento descrito por Laemli (22). Las condiciones de corrido fueron $150 \mathrm{~V}, 80 \mathrm{~mA}$, $90 \mathrm{~min}$; los geles fueron teñidos en azul de Coomassie G-250.

Dot-Blot. La especificidad de las IgY purificadas fue evaluada por Dot-Blot (23) fijando $1.5 \mathrm{mg}$ de los diferentes antígenos (los péptidos sintéticos correspondientes y los extractos de cerebro de rata postnatal y adulta).

ELI SA. Se realizó un ELISA indirecto para la cuantificación de IgY específicas según Perlmann y Perlmann (24), con pequeñas variaciones: los pozos de la placa NUNCMaxisorp fueron sensibilizados con $100 \mathrm{ml}$ de los péptidos sintéticos $(1 \mathrm{mg} / \mathrm{ml}) 0$ $100 \mathrm{ml}$ de extractos de cerebro de rata con concentración de proteína total $4 \mathrm{mg} / \mathrm{ml}$, todos ellos diluidos en proporción 1:9 con tampón carbonato $50 \mathrm{mM}, \mathrm{pH} 9.6 \pm 0.2$; la placa fue incubada a $37^{\circ} \mathrm{C}, 3 \mathrm{~h}$ y luego toda la noche a $4 \stackrel{\circ}{ } \mathrm{C}(\sim 12 \mathrm{~h})$. 
Terminada la incubación se retiraron las muestras y se lavaron los pozos con PBStween $0.1 \%(\mathrm{v} / \mathrm{v})$. El bloqueo se realizó con $200 \mathrm{ml}$ de $10 \%$ ( $\mathrm{v} / \mathrm{v}$ ) de suero fetal bobino (SFB) en PBS y se incubó por una hora a 37으. Se retiró el PBS-SFB y se agregó $100 \mathrm{ml}$ del anticuerpo primario $(1 \mathrm{mg} / \mathrm{ml}$ lgY pura), se incubó a $37^{\circ} \mathrm{C}$, 1 h y 4 으 durante toda la noche; pasado este tiempo se retiró la solución de anticuerpo y se lavó tres veces con PBS-tween $0.1 \%(\mathrm{~V} / \mathrm{v})$, y se aplicó $100 \mathrm{ml}$ de anticuerpo secundario (anti-gallina fabricado en conejo acoplado a peroxidasa (Sigma, St Louis, MO, USA) 1:2000), en cada uno de los pozos. Se Incubó a $3700 \mathrm{C}$, $1 \mathrm{~h}$, se lavó 5 veces con PBS-tween $0.1 \%$ ( $v / v)$ y se agregó a cada pozo $100 \mathrm{ml}$ de la solución reveladora ( $5 \mathrm{ml}$ de $2,2^{\prime}$ azino-bi(3'etilbenzotiazoline-6-ácido-sulfónico) (ABTS) (Sigma, St Louis, MO, USA) al 6\% (p/v) en tampón citrato-fosfato $\mathrm{pH} 5.0 \pm 0.2$ y $5 \mathrm{ml}$ de $\mathrm{H}_{2} \mathrm{O}_{2}$ al $30 \%(\mathrm{v} / \mathrm{v})$ ).

Se determinó la $A_{b S_{415 n m}}$ en un lector de ELISA, modelo 550 (BioRad $^{\mathrm{TM}}$ ) a los 15, 30, 45 y 60 minutos de reacción. Para los controles se sensibilizaron los pozos de las placas con el péptido sintético correspondiente y se tomó como anticuerpo primario un extracto crudo proveniente de la yema de huevos de gallinas no inmunizadas.

\section{Solubilización del complejo intacto del} receptor. Los cerebros de ratas se homogenizaron por separado en tampón Tris$\mathrm{HCl} 50 \mathrm{mM}, \mathrm{pH} 9.0 \pm 0.2$, que contenía parametil-sulfonil-fluoruro (PMSF) $0.5 \mathrm{mM}$, leupeptina $1 \mathrm{~g} / \mathrm{ml}$ y pepstatina $1 \mathrm{mg} / \mathrm{ml}$ como inhibidores de proteasas; EDTA $2.5 \mathrm{mM}$ y deoxicolato de sodio $1 \%(p / v)$. Luego de la homogenización completa de los cerebros en politrón (Virtis 23), cada extracto se mantuvo, en agitación constante a $37^{\circ} \mathrm{C}$, $1 \mathrm{~h}$. El extracto obtenido se centrifugó a $100,000 \times \mathrm{g}$ en centrifuga BECKMAN L-70, $1.5 \mathrm{~h}, 4^{\circ} \mathrm{C}$ (dos veces) (25). El sobrenadante fue dializado, dos veces contra tampón Tris$\mathrm{HCl} 50$ mM, pH $7.6 \pm 0.2$ con Tritón X-100 al $0.1 \%(\mathrm{v} / \mathrm{v})$. Nuevamente se centrifugó a $90,000 \times$ g, 1 h y se descartó el "pellet" y se conservó el extracto crudo a $-70^{\circ} \mathrm{C}$ hasta su utilización. La concentración de proteína fue determinada por Bradford (21). Los extractos fueron analizados por SDS-PAGE, $7.5 \%$ según Laemli (22) y las condiciones del corrido fueron $150 \mathrm{~V}, 80 \mathrm{~mA}, 90$ minutos.

\section{RESULTADOS}

A partir de las secuencias de las subunidades NR3A y NR3B de cerebro de rata, reportadas en la base de datos de NCBI (código de acceso 5305435 y 20376816 respectivamente), se diseñaron 2 péptidos sintéticos correspondientes a cada subunidad (pNR3A: residuos 299-318; pNR3B: residuos 395-416).

La prueba de ELISA realizada al extracto de los huevos colectados diariamente reportó un incremento considerable en la $A b_{415 n m}$ de IgY específica desde el día 15 y especialmente hacia el día 32 para la IgY antiNR3A y hacia el día veinte para la IgY antiNR3B (Figura 1).

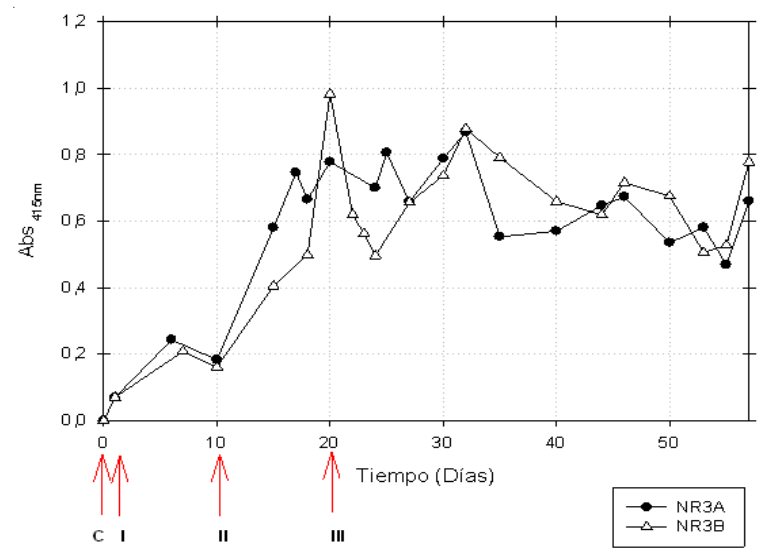

Figura 1. Detección de IgY específica durante el periodo de recolección de huevos. C. Extracto de IgY de gallina control respectivo I. Día siguiente a la inoculación II. Día del primer refuerzo, III. Día del segundo refuerzo.

Los extractos obtenidos a partir de la yema de huevo después del segundo refuerzo, realizado después del día 20, fueron utilizados para purificar las IgY específicas, para lo cual, se realizó inicialmente una precipitación con sulfato de amonio de las inmunoglobulinas y otras proteínas, (Figura 2A) $(19,26,27)$. De acuerdo con los perfiles cromatográficos para IgY antiNR3A e IgY antiNR3B (Figuras 3A y 3B), fue posible comprobar la efectividad de la separación por interacciones tiofílicas y se mostró el perfil de cada fracción obtenida (Figura 2B); una fracción retenida por el 


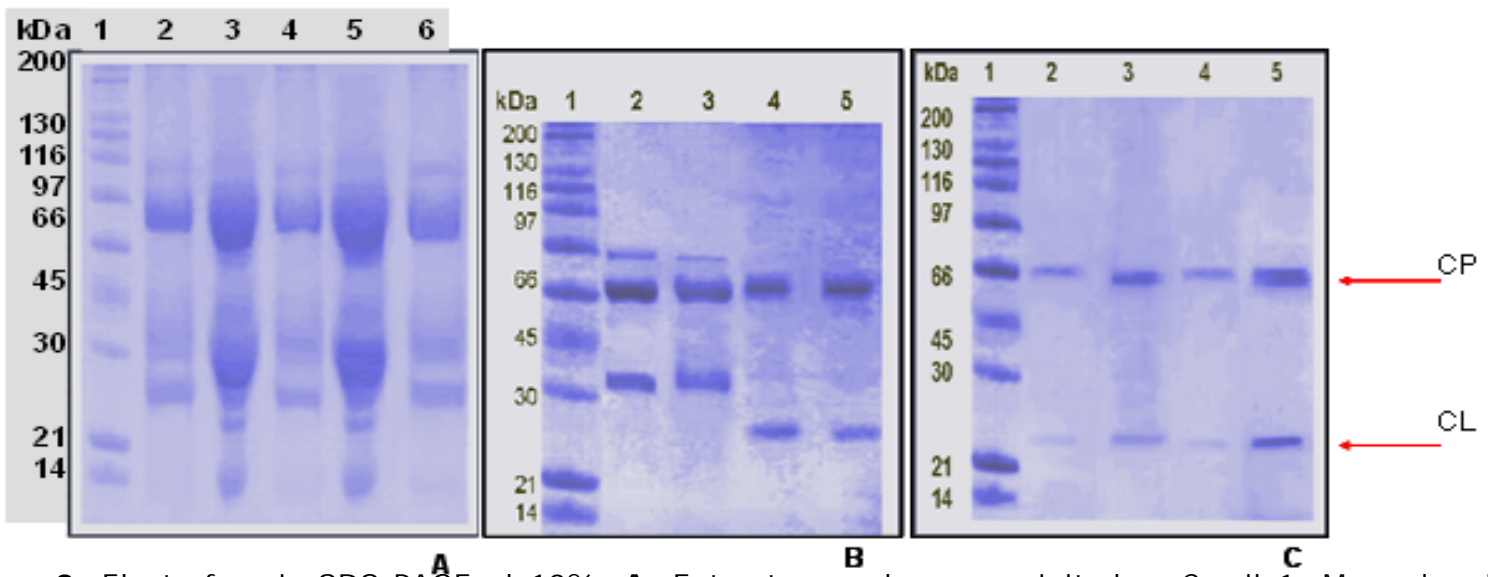

Figura 2. Electroforesis SDS-PAGE al 10\%. A. Extractos crudos y precipitados. Carril 1. Marcador de peso molecular (Wide range 6.500-205.000 Da, Sigma). Carril 2 y 4. Extractos antiNR3A precipitados con sulfato de amonio y con PEG respectivamente. Carril 3. Extracto crudo con antiNR3A. Carril 5. Extracto crudo con antiNR3B. Carril 6. Extracto precipitado con sulfato de amonio antiNR3B. B. Extractos de la cromatografía tiofílica. Carril 1. Marcador de peso molecular (Wide range 6.500-205.000 Da, Sigma). Carril 2 y 3. Eluido con Tampón A a partir de extracto con antiNR3A y antiNR3B respectivamente. Carril 4 y 5. Eluido con Tampón B a partir de de extracto con antiNR3A y antiNR3B respectivamente. C. Extractos de la cromatografía de afinidad. Carril 1. Marcador de peso molecular (Wide range 6.500-205.000 Da, Sigma). Carril 2. Retenido IgY antiNR3A. Carril 3. No retenido IgY (antiNR3A). Carril 4. Retenido IgY antiNR3B. Carril 5. No retenido IgY (antiNR3B).

adsorbente tiofílico que corresponde a las cadenas pesada y liviana de las IgY totales y una fracción que no interactuó con el grupo activo del soporte y que corresponde a las demás proteínas. Los resultados de concentración de la fracción retenida se encontraban alrededor de $1.5 \mathrm{mg} / \mathrm{ml}$, lo que indicó que el contenido de IgY totales que correspondía entre el 20 y $25 \%$ de la proteína soluble presente en el extracto crudo.

De acuerdo con los perfiles cromatográficos, (Figuras 3C y 3D) fue posible la separación de las IgY específicas (fracción retenida)
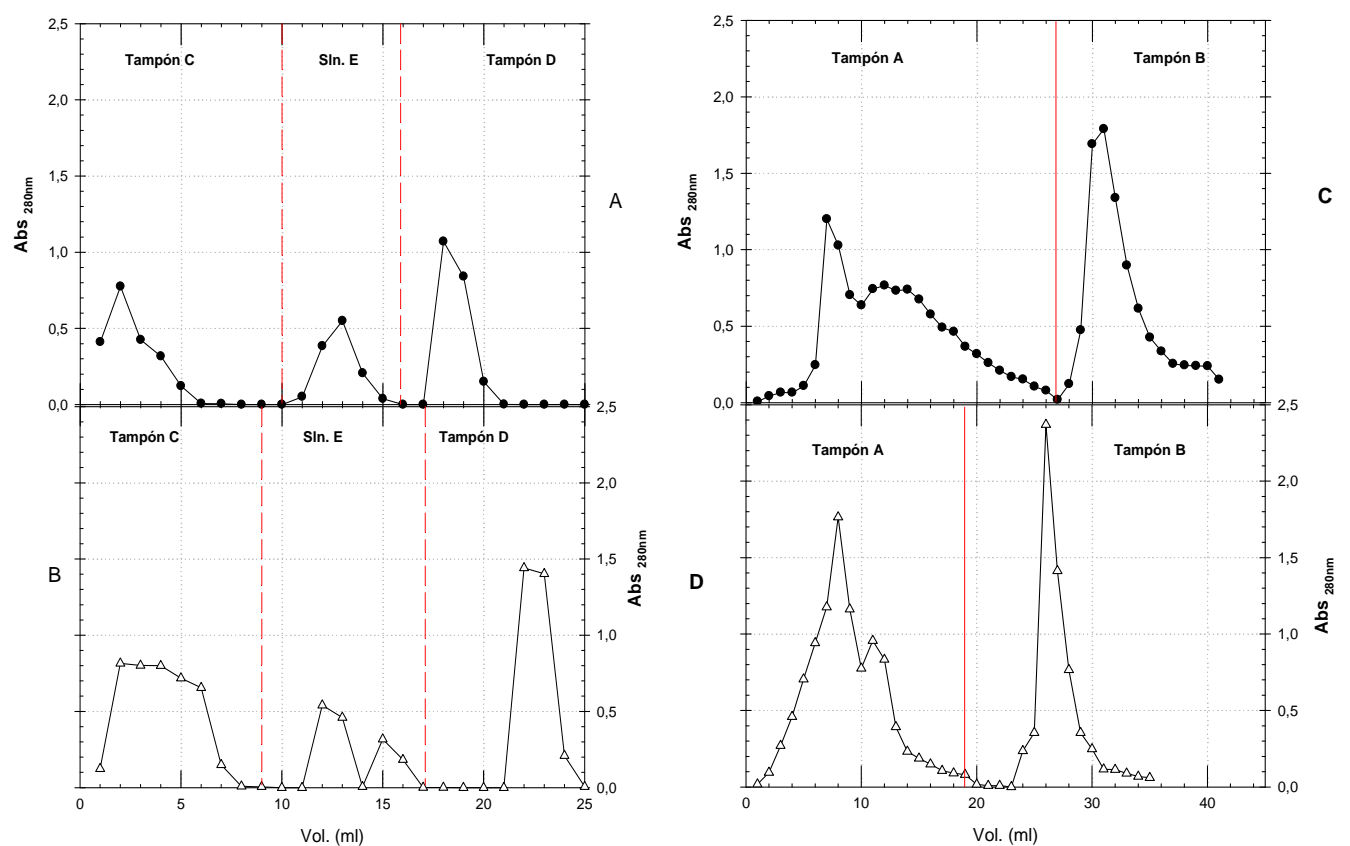

Figura 3. A y B. Cromatografía Tiofílica. A. Extracto IgYantiNR3A. B. Extracto precipitado IgYantiNR3B. C y D. Cromatografía de afinidad. C. IgY antiNR3A. D. IgY antiNR3B: Tampón A (fosfato $50 \mathrm{Mm}, \mathrm{pH} 7.5 \pm$ 0.2 , Sulfato de sodio $0.5 \mathrm{M}$ ), Tampón $\mathrm{B}$ : (fosfato $50 \mathrm{mM} \mathrm{pH} 7.5 \pm 0.2$ ), Tampón C (tampón fosfato $0.1 \mathrm{M}$ pH $7.5 \pm 0.2$ ), Tampón D (Glicina $0.5 \mathrm{M} \mathrm{pH} 2.4 \pm 0.2$ ) y SIn E. (Péptido sintético $1 \mathrm{mg} / \mathrm{ml}$ en tampón C). 
de las IgY totales (fracción eluida), lo que también se corroboró por SDS-PAGE (Figura 2C). En este paso de purificación se arrastró péptido empleado para la elusión disuelto con la IgY específica, por lo cual fue necesario dializar las fracciones para eliminar el péptido y obtener la IgY específica pura y evitar las interferencias. De acuerdo con los resultados de la cuantificación, el contenido de IgY específica osciló entre $\sim 3$ y $5 \%$ de la IgY total.

Los ensayos de ELISA (Figuras 4A y 4B) mostraron la presencia de IgY específica y
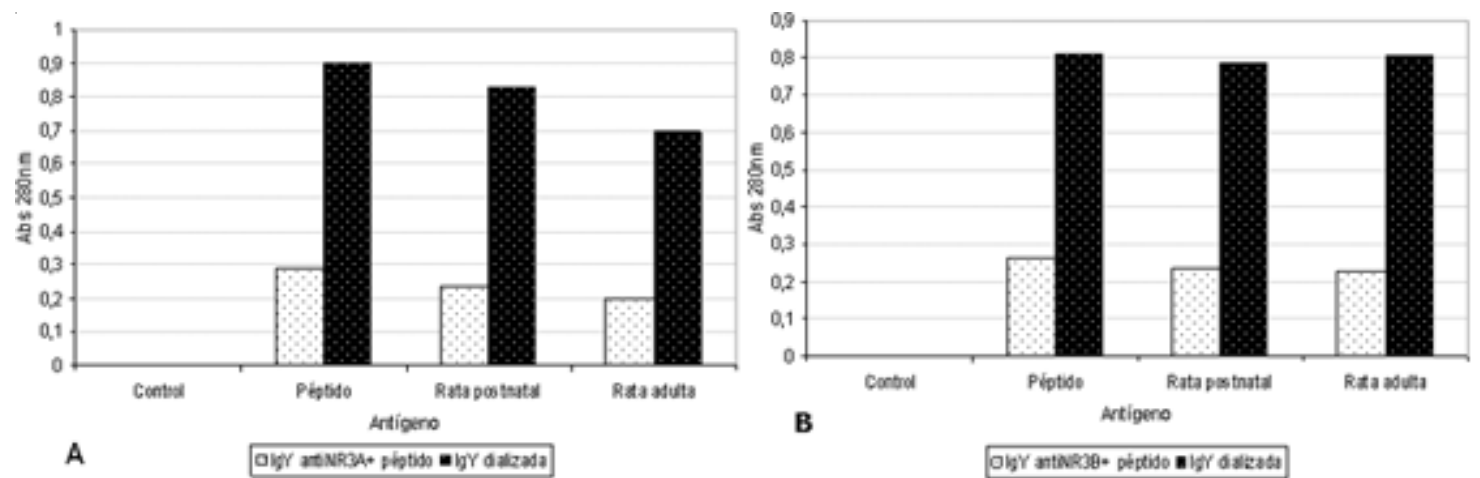

Figura 4. Ensayo de ELISA frente a diferentes antígenos A. IgY antiNR3A B. IgY antiNR3B. En blanco las fracciones de IgY antes de diálisis retenidas, obtenidas en la cromatografía de afinidad y en oscuro fracciones IgY posteriormente dializadas en Tampón Fosfato 50Mm, pH 7.5 \pm 0.2 .

el efecto de la diálisis sobre el reconocimiento del anticuerpos, presentándose reconocimiento aún en diluciones $1 / 1600$ (datos no mostrados).

De igual manera, se comprobó la efectividad de los anticuerpos purificados, según muestra el Western-Blot (Figura 5), donde se observó una sola banda de proteína (100-130 kDa) que corresponde a los pesos moleculares predichos para las subunidades NR3A y NR3B. Finalmente, según los resultados del ensayo de ELISA (Figura 4), las IgY específicas permitieron detectar que la subunidad NR3A
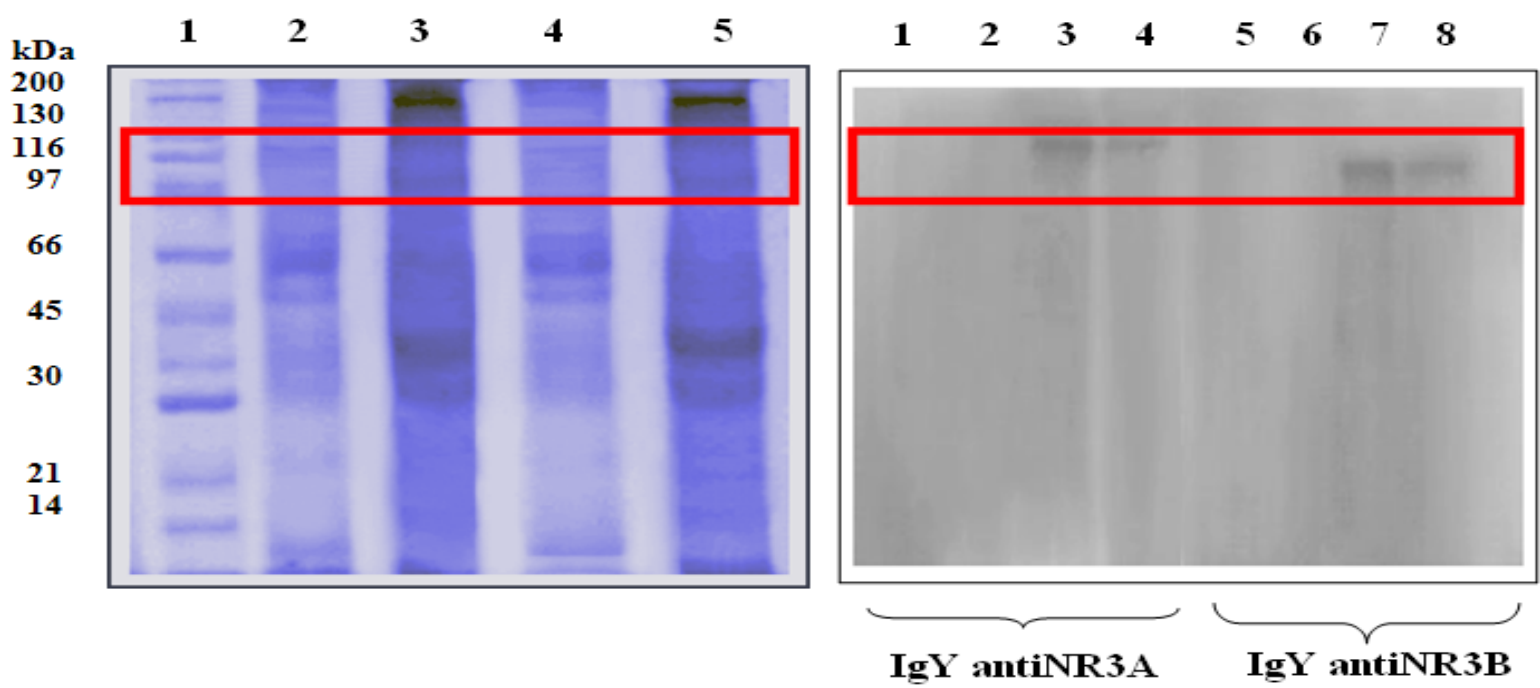

Figura 5. Identificación de las subunidades NR3A y NR3B en extracto de cerebro de rata. A. Electroforesis SDS-PAGE 7.5\%. Carril 1. Marcador de peso molecular (Wide range 6.500-205.000 Da, Sigma). Carril 2 y 3 sobrenadante y "pellet" del homogenizado de rata postnatal. Carril 4 y 5 sobrenadante y "pellet" del homogenizado de rata adulta. B. "Western-Blot" a partir de extracto de rata postnatal. Carril 1 y 2. Condiciones reductoras frente a IgYantiNR3A. Carril 3 y 4 Condiciones no reductoras frente a IgYantiNR3A. Carril 5 y 6 . Condiciones reductoras frente a IgYantiNR3B. Carril 7 y 8 Condiciones no reductoras frente a IgYantiNR3B. 
se encuentra en una mayor proporción en el cerebro de rata postnatal que en cerebro de rata adulta; la subunidad NR3B no presentó variación en estas edades.

\section{DISCUSIÓN}

En diferentes estudios, los anticuerpos monoclonales y policlonales han sido utilizados para identificar algunas de las subunidades del receptor NMDA $(2,7,28$, 29) y para su identificación "in situ" de la subunidad NR3B en motoneuronas de ratón (30). De acuerdo con los resultados obtenidos, fue posible identificar la subunidad NR3 del receptor NMDA mediante la producción y purificación de anticuerpos policlonales generados en gallinas Hy Line Brown.

Los péptidos diseñados, que fueron utilizados como antígenos en las inoculaciones, no se encuentran localizados en los dominios transmembranales según la predicción realizada en TMpred (31), lo que aseguró que el segmento de las subunidades que fuera reconocido por los anticuerpos purificados, hiciera parte de una zona expuesta del receptor.

Los protocolos de extracción, precipitación con sulfato de amonio al $60 \%$ (p/v) $(19,26$, 27) y de cromatografía tiofílica fueron efectivos para purificar IgY totales, gracias a que en la activación de la resina empleada para la cromatografía tiofílica, los grupos divinilsulfona acoplados, son bloqueados al reaccionar con un ligando inerte de bajo peso molecular (b-mercaptoetanol), resultando en un grupo sulfona en proximidad a un grupo tioéter; de esta manera se generó un ligando con alta especificidad adsorbente para proteínas con características estructurales similares a la IgY, capaces de donar un electrón que es aceptado por el ligando, en presencia de sales formadoras de estructura $(19,32)$.

La cromatografía de interacción tiofílica mostró una unión selectiva entre el adsorbente y las inmunoglobulinas. Esta unión denominada adsorción tiofílica es una clase de interacción altamente selectiva dependiente de fuerza iónica promovida por sales no caotrópicas (32), como es el caso del sulfato de sodio empleado en este proceso. Al obtener entre el 20 y $25 \%$ de la proteína total soluble, se demostró que el método fue más eficiente que el propuesto por Hansen (19), trabajo en el cual la IgY total obtenida correspondía al $17 \%$ de la proteína soluble extraída; diferencia que posiblemente se deba a que en este trabajo se acopló mayor cantidad de adsorbente a la resina. El rendimiento de IgY pura, coincide con algunos reportes de la literatura donde se menciona que la producción de IgY específica para un antígeno inoculado oscila entre 2 y $10 \%$ de las IgY totales (12), lo cual indica que la combinación de los dos métodos cromatográficos empleados para la purificación de los anticuerpos, resultó ser una estrategia acertada, y aseguró la obtención de IgY específica altamente pura capaz de reconocer los epítopes conformacionales de la subunidad NR3 en los extractos de rata postnatal y adulta.

En cuanto a la expresión de la subunidad NR3A de acuerdo con la edad, los resultados coinciden con los obtenidos para los transcriptos de cerebro de ratón (3), que indican que la expresión permanece elevada durante las primeras semanas postnatales pero en la edad adulta disminuye gradualmente. Para la subunidad NR3B no se encontró diferencia considerable en la expresión dependiendo de la edad, por lo cual se puede afirmar que en rata el comportamiento en la expresión en la etapa postnatal y la edad adulta, es similar a lo que ocurre en el ratón, según lo indican algunos reportes (30).

En este trabajó se produjeron anticuerpos policlonales tipo IgY contra los péptidos sintéticos correspondientes a las subunidades NR3A y NR3B, y se detectaraon estas subunidades del receptor NMDA en extractos de cerebro de rata postnatal y adulta, encontrando que la subunidad NR3A se encuentra menos expresada que la NR3B en edad adulta y que en edad postnatal la NR3A se expresa aún más que en la edad adulta. Según la información disponible y a diferencia de otros trabajos realizados con 
subunidades recombinantes, esta es la primera investigación que emplea extractos de cerebro de rata y por tanto la proteína nativa, lo cual muestra la especificidad de los anticuerpos generados y adentra en el conocimiento del receptor NMDA y su relación con la regulación de la memoria espacial. De otro lado, teniendo en cuenta la especificidad, facilidad, la economía y el rendimiento alcanzado en la producción de IgY se demuestra una vez más que esta metodología es de gran utilidad en el reconocimiento cruzado de moléculas complejas en especies productoras de IgG.

El receptor ionotrópico de glutamato NMDA se ha identificado en las últimas dos décadas, como la molécula central de todos los procesos que ocurren en células excitables y aún en otro tipo de células como osteoblastos (33). Dada la importancia del receptor NMDA en los procesos de aprendizaje y la formación de la memoria, mediados por el transporte de calcio a través del canal asociado a dicho receptor, se hace necesario comprender el funcionamiento del mismo. En trabajos anteriores se logró el diseño computarizado de un péptido sintético (MK-801) (34) que al ser evaluado en ratas variedad Wistar, demostró que favorece los procesos de memoria espacial y aprendizaje con un nivel de significancia $p \leq 0.05$; mejora que fue observada en el $50 \%$ de los sujetos. Los péptidos sintéticos utilizados en este estudio (35), correspondieron a una región expuesta de las subunidades regulatoria
NR3A y NR3B del receptor NMDA. El haber producido IgY contra estos péptidos y el haber demostrado el reconocimiento por parte de estos anticuerpos en células suspendidas de cerebro de rata facilita la puesta a punto de un modelo animal en que se puede hacer el seguimiento de la influencia de péptidos como el MK-801 en la sobre-expresión de las subunidades NR3A y NR3B como posible indicador de mejora en la memoria espacial y el aprendizaje.

Dado que la expresión de las subunidades regulatorias NR3A y NR3B del receptor NMDA es diferencial y que depende de la edad y la Iocalización en el Sistema Nervioso Central (SNC), y como se muestra en este estudio, los anticuerpos IgYaNR3A y IgYaNR3B permitirán a corto plazo desarrollar estudios inmuno-histoquímicos en ratas para seguir la expresión localizada "in vivo" bajo diferentes estímulos.

\section{Agradecimientos}

A la Fundación Instituto de Inmunología de Colombia por la síntesis de los péptidos y a los doctores Gerardo Pérez y Nohora Vega del grupo de investigación en Proteínas de la Universidad Nacional de Colombia por compartir sus conocimientos y brindarnos su ayuda en el desarrollo de este trabajo. A la Pontificia Universidad J averiana por el apoyo financiero (proyecto No.1715).

\section{REFERENCIAS}

1 Dingledine R, Borges K, Bowie D, Traynelis $S$. The glutamate receptor ion channels. Pharmacol Rev 1999; 51: 7-61.

2 Pérez I, Schulteis C, Contractor A, Lipton S, Trimmer J, Sucher N, et al. Assembly with the NR1 subunit is required for surface expression or NR3A-containing NMDA Receptors. J Neur 1999; 21: 12281237.
3 Cibarra S, Gahn L, Pecht G, Heinemann S, Sevarino K. Cloning and characterization of chi-1: A developmentally regulated member of a novel class of the ionotropic glutamate receptor family. J Neur 1995; 15: 6498-6508.

4 Sucher N, Akbarian S, Chi C, Leclerc C, Awobuluyi $M$, Deitcher $D$, et al. Developmental and regional expression pattern of a novel NMDA receptor-like subunit (NMDAR-L) in the rodent brain. J Neur 1995; 15: 6509-6520. 
5 Das S, Sasaki Y, Rothe T, Premkumar L, Takasu M, Crandall J, et al. Increased NMDA current and spine density in mice lacking the NMDA receptor subunit NR3A. Nature 1998; 393: 377-381.

6 Sun L, Margolis F, Shipley M, Lidow M. Identification of a long variant of $M R N A$ encoding the NR3 subunit of the NMDA receptor: its regional distribution and developmental expression in the rat brain. FEBS Let 1998; 441: 392-396.

7 Nishi $M$, Heather $\mathrm{H}$, Hai-Ping L, Mitsihiru $\mathrm{K}$, Yasunori $\mathrm{H}$. Motoneuron specific expression of NR3B, a novel NMDA type glutamate receptor subunit that works in a dominant negative manner. J Neur 2001; 21: 1-6.

8 Madden D. The structure and function of glutamate receptor ion channels. Nature 2002; 3: 91-101.

9 Morrison S, Mohammed M, Wims L, Trinh $R$, Etches R. Sequences in antibody molecules important for receptor mediated transport into the chicken egg yolk. Mol Immunol 2001; 38: 619-625.

10 Patterson R, Youngner J, Weigle W, Dixon F. Antibody production and transfer to egg yolk in chickens. J Inmunol 1962; 89: 272-278.

11 Warr G, Magor K, Higgins D. IgY: clues to the origins if modern antibodies. I mmunol Today 1995; 16: 392-398.

12 Narat M. Production of antibodies in chickens. Food Technol Biotechnol 2003; 41: 259-267.

13 IBCP. Pôle Biol nformatique Lyonnais, Clustal W PBIL. URL disponible http:// n psa-pbil. i bcp.fr/cgi-bin/ npsa_automat.pl?page=/NPSA/ npsa_clustalw.html.

14 Caprino L, Han G. The 9fluorenylmethoxycarbonyl group. J Org Chem 1972; 37: 3404-3409.

15 Merrifield R. Solid phase peptide synthesis
II. The synthesis of a tetrapeptide. J Am Chem Soc 1963; 85: 2149-2153.

16 Akita E, Nakai S. Isolation and purification of inmunoglobulins from egg yolk. J Food Sci 1992; 57: 629-634.

17 Gassmann M, Thömmes P, Weiser T, Hübscher $U$. Efficient production of chicken egg yolk antibodies against a conserved mammalian protein. FASEB J 1990; 4: 2528-2532.

18 Jensenius J, Koch C. Antibodies packaged in eggs. Immunochemistry. 1997: IRL Press Oxford.

19 Hansen P, Scoble J, Hanson B, Hoogenraad N. Isolation and purification of immunoglobulins from chicken eggs using thiophilic interaction chromatography. J Inmunol Met 1998; 215: 1-7.

20 Hermanson G, Mallia A, Smith P. I mmobilized Affinity Ligand Techniques. 1992; New York, USA: Academic Press Inc.

21 Bradford MM. A rapid and sensitive method for the quantitation of microgram quantities of protein utilizing the principle of protein - dye binding. Anal Biochem 1976; 72 : 248 - 254.

22 Laemmli UK. Cleavage of structural proteins during the assembly of the head of bacteriophage T4. Nature 1970; 227: 680-685.

23 Woof J, Burton D. Human antibody - Fc receptor interactions iluminated by cristal structures. Nat Rev Inmunol 2004; 4: 111.

24 Perlmann H, Perlmann P. Enzyme-Linked Immunosorbent Assay. Cell Biology: A Laboratory Handbook. 1994: Academic Press Inc.

25 Wenthold R, Blahos J, Huh K, Petralia R. Detergent solubilization and immunoprecipitation of native NMDA receptors. In NMDA Receptor Protocols. 1999: Humana Press. 
26 Akita E, Li-Chan E. I solation of bovine immunoglobulin $\mathrm{G}$ subclasses from milk, colostrum and whey using immobilized egg yolk antibodies. J Dairy Sci 1998; 81: 54-63.

27 Meulenaer B, Huyghebaert A. Isolation and purification of chicken egg yolk immunoglobulins: A review. Food Agricul Immunol 2001; 13: 275-288.

28 Andersson O, Stenqvist A, Attersand A, Von $G$. Nucleotide sequence, genomic organization, and chromosomal localization of genes encoding the human NMDA receptor subunits NR3A and NR3B. Genomics 2001; 78: 178-184.

29 Sasaki Y, Rothe T, Premkumar L, Das S, Cui J, Talantova $M$, et al. Characterization and comparison of the NR3A subunit of the NMDA receptor in recombinant systems and primary cortical neurons. J Neurophysiol 2002; 87: 2052-2063.

30 Matsuda K, Kamiya Y, Matsuda S, Yuzaki $M$. Cloning and characterization of a novel NMDA receptor subunit NR3B: a dominant subunit that reduces calcium permeability. Mol Brain Res 2002; 10: 4352.
31 TMpred. Prediction of transmembrane regions and orientation Switzerland. http: / /www. ch. embnet.org/software/ TMPRED_form.html.

32 Porath J, Maisano F, Belew M. Thiophilic adsorption - a new method for protein fractionation. FEBS Let 1985; 185: 306310.

33 Villegas V, Zarante I, Lareo L. Estudio preliminar de los polimorfismos del gen GRIN-1 del receptor NMDA en una población sana colombiana. Univ Scient 2006; 11: 49-60.

34 Oyuela R, Lareo L, Muñoz L, Morales L, Echevery S, Uribe A, et al. Efecto en el aprendizaje y la memoria espacial de un péptido sintético en ratas: estudio preliminar. Psicol Caribe 2004; 13: 114.

35 Méndez G. Producción y purificación de IgY contra la subunidad NR3 del receptor de Glutamato tipo NMDA aislado de cerebro de rata.[Tesis de Maestria]. Bogotá, D.C, Colombia: Pontificia Universidad Javeriana, Facultad de Ciencias, Departamento de Nutrición y Bióquimica; 2005. 